\title{
The System of Merit in Common Law: Origins, evolution, and the current state of affairs
}

\section{O Sistema de Mérito no Âmbito da Common Law: Origens, Evolução e Atualidade}

\author{
CLÁUDIA S. COSTA ${ }^{a}$ \\ ANTÓNIO F. TAVARES ${ }^{b}$
}

\begin{abstract}
Resumo
Este capítulo discute as origens e a evolução da aplicação do sistema de mérito nos Estados Unidos da América (EUA), com enfoque na tensão primordial entre a busca da eficiência através da competência técnica da burocracia e a sua responsabilização política perante os eleitos e seus nomeados. Os autores começam por descrever o sistema de despojos que vigorou nos EUA durante grande parte do século XIX, evidenciando os fatores que conduziram à sua crítica e substituição pelo sistema de mérito plasmado no Pendleton Act. Posteriormente, é descrita a evolução do sistema ao longo do século $X X$, identificando os grandes desafios e alterações que levaram à sua modernização. 0 capítulo encerra com a identificação dos traços preponderantes do sistema de mérito na atualidade.
\end{abstract}

Palavras-chave: sistema de mérito, sistema de despojos, clientelismo, Pendleton Act.

\begin{abstract}
This chapter discusses the origins and evolution of the merit system application in the United States of America. It focuses on the tension between the pursuit of efficiency through the technical competence of the bureaucracy and the accountability of its electoral policy and its nominees. The authors begin by describing the system of spoils that prevailed in the United States during much of the nineteenth century, highlighting the patterns that prevail in their critique and their replacement by the merit system embodied in the Pendleton Act. The evolution of the system throughout the twentieth century is then described, identifying the great challenges and the changes that led to its modernisation. The chapter concludes with an identification of current prevailing features of the merit system.
\end{abstract}

Keywords: merit system, spoils system, patronage, Pendleton Act.

\footnotetext{
a Doutorada em Ciências da Administração na Escola de Economia e Gestão da Universidade do Minho; Professora Adjunta na Escola Superior de Comunicação, Administração e Turismo do Instituto Politécnico de Bragança (EsACT-IPB); Membro efetivo do Centro de Investigação, Desenvolvimento e Inovação em Turismo (CiTUR Guarda); Membro colaborador do Centro de Investigação em Ciência Política (CICP). Email: claudia@ipb.pt

b Doutorado em Administração Pública pela Reubin O’D. Askew School of Public Administration and Policy, Florida State University; Professor Associado com Agregação na Escola de Economia e Gestão da Universidade do Minho e membro efetivo do Centro de Investigação em Ciência Política (CICP).

Email: atavares@eeg.uminho.pt
} 


\section{Introdução}

A função pública nos Estados Unidos da América é distinta da maioria dos países, não apenas devido à natureza federal do seu sistema governamental, que implica a existência de milhares de serviços públicos diferentes na administração federal, em cada um dos estados e dentro das subunidades de cada estado, mas também por se tratar de um sistema grandioso, descentralizado e fragmentado, que constitui um instrumento e símbolo político (Anagnoson, 2011). Seria demasiado ambicioso traçar a evolução de todo o universo da Administração Pública americana em perspetiva comparada com os países da common law e verdadeiramente inviável fazê-lo no espaço limitado de um artigo. Por esse motivo, foi nossa opção focar esta análise na evolução das práticas de mérito no âmbito da administração federal, procurando retratar as origens, a evolução e o estado atual da função pública americana neste domínio.

Há muito que a ciência política e a ciência da administração têm demonstrado interesse pelos procedimentos de recrutamento e seleção dos funcionários públicos e pelo reconhecimento do mérito nas diferentes fases do ciclo de emprego. Durante grande parte do século XIX, entre as Administrações de Andrew Jackson e de James Garfield, a administração federal americana caracterizou-se por um sistema de despojos, que valorizava a lealdade política e a distribuição de cargos administrativos aos apoiantes do governo-do-dia, com o consequente negligenciar da necessidade de desenvolver um trabalho competente. O sistema de despojos dominou a política de pessoal do governo americano, em grande medida porque os políticos reconheciam os benefícios associados à ocupação de cargos públicos por indivíduos leais à mesma persuasão política (Ruhil e Camões, 2003; Ting, Snyder, Hirano e Folke, 2012).

No final do século XIX, iniciou-se um movimento de reforma (Progressive Reform) que procurou afastar a administração do anterior sistema de despojos e aplicar um sistema de mérito à administração federal modelado a partir da Prússia weberiana e do sistema britânico. O objetivo era promover a competência neutral dos funcionários públicos relativamente aos políticos eleitos, de modo a valorizar o conhecimento técnico em detrimento das lealdades políticas (Kaufman, 1956).

Ao longo do século xx, a administração federal americana foi pontuada por uma tensão constante entre a valorização do mérito e da competência técnica por um lado e a necessidade de responsabilização perante os políticos eleitos e os seus nomeados por outro (Tsao e Worthley, 2009). A partir da 
década de 1960, esta tensão complexificou-se com a introdução de critérios de equidade e justiça social no tratamento de alguns grupos sociais discriminados no passado, como sejam as mulheres, as minorias e os veteranos de guerra, entre outros. $\mathrm{O}$ mérito continuou a ser o critério dominante no recrutamento, seleção e compensação dos funcionários públicos, mas este conjunto de valores associados ao progresso dos direitos civis introduziu nuances que convém explorar.

Este texto encontra-se organizado em cinco secções, incluindo a conclusão. Após esta introdução, a primeira secção discute o estabelecimento e a expansão do sistema de despojos, vigente nos Estados Unidos da América durante grande parte do século XIX. A segunda secção descreve os acontecimentos que levaram ao declínio do sistema de despojos e sua substituição por um sistema baseado no mérito, de lenta consolidação a partir do final do século XIX e ao longo da primeira metade do século Xx. A terceira secção analisa as condições que favoreceram a manutenção da mesma legislação - o Pendleton Act (1883-1978) - ao longo de quase cem anos como pilar do sistema de mérito da Administração Pública norte-americana. A quarta secção discute o impacto do Relatório Gore e do movimento de Reinvenção do Governo na aplicação do sistema de mérito ao nível da administração federal. A conclusão reflete sobre o estado atual do sistema de mérito no contexto das administrações públicas em estados marcados pela common law.

\section{O Contexto Histórico da Função Pública nos Estados Unidos: O Sistema de Despojos}

A história da Administração Pública nos Estados Unidos da América precede a própria Revolução Americana e a Declaração da Independência de 1776. No tempo da administração pela Coroa Britânica, os governadores coloniais eram nomeados com base no privilégio, influência e favoritismo, sendo o mérito dos nomeados, na maior parte das vezes, um critério irrelevante (Anagnoson, 2011). Os funcionários ou eram admitidos na base do nepotismo ou do clientelismo político (patronage), ou pura e simplesmente compravam o cargo público, que, em muitos casos, transmitiam aos seus descendentes.

Historicamente, a implementação do sistema de despojos nos Estados Unidos da América é atribuída ao presidente Andrew Jackson, mas o clientelismo serviu, desde o início da nação americana, como um valioso recurso político (Kutler, 2003). A administração do primeiro presidente, George Washington (1789-1797), manteve a nomeação de alguns funcionários públicos, em parti- 
cular os homens das elites que haviam dominado a política colonial, assegurando que esses nomeados compartilhavam as suas opiniões políticas (Anagnoson, 2011; Kutler, 2003).

No mesmo sentido, Thomas Jefferson (1801-1809) e os seus sucessores seguiram a prática adotada pelo presidente Washington, destituindo os titulares dos cargos para serem ocupados por indivíduos de confiança política (Kutler, 2003). Os primeiros seis presidentes valorizaram a lealdade política, mas associaram-lhe o prestígio social e a capacidade para aprender o exercício de funções na Administração Pública. De um modo geral, os nomeados foram capazes de desenvolver o seu trabalho com honestidade, eficiência e eficácia, defendendo o interesse público em detrimento do seu papel na política partidária (Rosenbloom, 1989). Esta prática política fazia sentido, na medida em que os homens que rodearam os pais da democracia americana eram os mais educados e mais experientes para governar. Nesse tempo, privilégio e mérito não eram conceitos distintos (Schuman e Olufs III, 1988) e a política de pessoal era uma política de governo pelos gentlemen ${ }^{[1]}$ (Rosenbloom, 1989). A consequência desta prática foi a criação de uma elite administrativa bem preparada, mas não representativa dos diferentes estratos sociais do país.

Enquanto política do governo federal, o sistema de despojos ${ }^{[2]}$ foi introduzido e generalizado durante a administração do presidente Andrew Jackson (1829-1837), sendo o seu termo atribuído ao famoso discurso do senador americano William L. Marcy: «nothing wrong in the rule, that to the victor belong the spoils of the enemy» (Anagnoson, 2011; McGrath, 2013). Segundo Anagnoson (2011), o sistema de despojos generalizou-se aos governos estaduais e locais do nordeste e ocidente do país. Nos estados do Sul continuou a vigorar o governo dos gentlemen, mesmo após a Guerra Civil (1861-1865).

A introdução do sistema de despojos ocorre num contexto de aumento da sofisticação das funções do governo, que obrigou a uma maior centralização de autoridade no âmbito do poder executivo. O presidente Andrew Jackson estava consciente da necessidade de fazer crescer a burocracia, mas também da necessidade de democratizar o acesso à função pública. A rotação de cargos proposta no âmbito do sistema de despojos era consistente com o espírito anti-intelectual que predominou durante a Presidência de Jackson, pois per-

\footnotetext{
${ }^{1}$ Em Português, governo pelos cavalheiros. A ocupação da alta administração dependia do background educacional e das grandes famílias aristocráticas (Rocha, 2005).

${ }^{2}$ Spoils system no original. Nome pelo qual ficou conhecido este sistema de clientelismo político.
} 
mitia democratizar o acesso, impondo menos requisitos de educação e classe à entrada na função pública (Schuman e Olufs III, 1988).

Para além dos efeitos sobre a democratização da função pública, o presidente Andrew Jackson considerava também que a nomeação como recompensa para o trabalho desenvolvido ao longo da campanha eleitoral deveria ser acompanhada pela continuação das atividades de campanha por parte dos nomeados (Kutler, 2003). Por outras palavras, tornou-se prática comum em cada administração os partidos políticos procurarem ativamente potenciais apoiantes, algo compreensível à luz do crescimento do poder dos partidos políticos durante este período. A administração do presidente Andrew Jackson e as administrações que se lhe sucederam usavam a burocracia com fins políticos e partidários. Os burocratas financiavam os partidos políticos em troca da nomeação para um determinado cargo.

O sistema dos despojos cresceu exponencialmente ao longo do século XIX e, no seu apogeu, os cidadãos não conseguiam obter um emprego público sem a recomendação de um político. A lealdade ao partido, refletida através das contribuições financeiras (até um máximo de cinco por cento do vencimento), constituía o critério primordial para garantir ou manter um emprego público (Maranto e Johnson, 2008). Em consequência, o conhecimento técnico, a formação e a competência não orientavam o recrutamento, a seleção ou a promoção dos funcionários públicos (Ruhil e Camões, 2003).

Embora este sistema promovesse uma maior participação na política, fornecendo incentivos ao envolvimento nas atividades partidárias, também colocava numerosos indivíduos incompetentes e corruptos em posições de poder (Denhardt, 1995). Cada nova administração substituía um grande número de funcionários públicos, distribuindo esses cargos aos seus aliados políticos, o que tornava quase impossível manter uma carreira estável na função pública. Em média, os funcionários públicos apenas permaneciam no cargo por um período de tempo correspondente ao mandato presidencial, e a maioria dos funcionários não tinha muita experiência nos cargos que desempenhava (Anagnoson, 2011). Além disso, uma grande parte do tempo do presidente era dedicada ao preenchimento de centenas de postos de trabalho na função pública (Denhardt, 1995).

Os efeitos do sistema de despojos foram dramáticos. Durante o século XIX, a história da administração federal dos Estados Unidos da América é pautada pelas remoções em massa de funcionários públicos sempre que uma nova administração iniciava funções de governação, bem como de todos os 
cargos de topo, incluindo o presidente e os funcionários do seu gabinete, colocando de parte as questões mais prementes da governação para lidar com as reivindicações mais agressivas daqueles que buscavam o poder (Anagnoson, 2011).

As primeiras pressões para a reforma da função pública surgiram na década de 1850, embora o seu impacto não tenha sido muito significativo (Ruhil e Camões, 2003). Muitos dos funcionários públicos que tinham sido escolhidos com base no sistema de despojos não usaram o sistema para promover os seus próprios subordinados, pelo que se notou algum interesse pelos ganhos de eficiência associados a uma maior permanência nos cargos. Em 1853, o Congresso aprovou a primeira legislação que exigia a realização de um exame para cargos na administração federal, em particular um teste de alfabetização e outras questões relacionadas com as próprias funções a desempenhar. No mesmo sentido, o Congresso aprovou também legislação estabelecendo escalas de remuneração e avaliação de desempenho (Anagnoson, 2011).

Todavia, as tentativas de reforma mais significativas só ocorreram após a Guerra Civil Americana (1861-1865). As forças que apoiaram a reforma no período pós-Guerra Civil resultaram essencialmente de interesses empresariais e dos próprios funcionários públicos. Os reformadores eram sobretudo críticos do ambiente de corrupção endémica e ineficácia generalizada resultantes do sistema de despojos. Estas práticas eram de tal modo intrínsecas à cultura política da administração federal que os jornais dispunham de secções para anúncios de candidatos a empregos dispostos a pagar a qualquer político que pudesse oferecer um cargo, pelo que a constante procura de posições na administração após cada eleição se tornou extremamente desagradável para a respectiva Presidência (Anagnoson, 2011).

Assim sendo, em 1864-1865, sob a Presidência de Abraham Lincoln, os membros republicanos do Congresso introduziram, pela primeira vez, a discussão sobre legislação da função pública na administração federal americana. Além disso, a luta entre o presidente Andrew Johnson (1865-1869) e o Congresso republicano sobre o controlo do clientelismo, desencadeou uma nova dimensão na reforma da função pública. Foi apenas uma questão de tempo até que a primeira legislação da função pública, da autoria de Thomas A. Jenckes, fosse aprovada em 1871. Foi então instituída uma Comissão da Função Pública, composta por sete membros, cuja tarefa principal consistia na formulação de regras e regulamentos apropriados para encetar uma reforma significativa da burocracia federal (Ruhil e Camões, 2003). 
Foi contra este sistema de despojos que se fizeram as reformas da função fública, em primeiro lugar em Inglaterra, com o Northcote-Trevelyan Report (1854), no qual se recomendava que a função pública deveria ser constituída por um corpo de jovens selecionados com base na competência e em exames à entrada (Horton, 2011; Parry, 2011). As reformas em Inglaterra influenciaram os Estados Unidos, tendo inspirado o Pendleton Civil Service Reform Act (1883). Estavam reunidas as condições para colocar fim a um longo período de clientelismo e corrupção durante o qual os funcionários públicos eram escolhidos com base na confiança política (Bilhim, 2017; Rocha, 2005).

\section{A Adoção do Sistema de Mérito no Âmbito da Common Law}

Nesta secção descrevemos a adoção do sistema de mérito no contexto anglo-saxónico, com particular destaque para os Estados Unidos da América. A principal fonte de inspiração legislativa da reforma da função pública da administração federal americana reside no Northcote-Trevelyan Report aprovado em 1854 e que representa um marco na adoção do sistema de mérito no Reino Unido.

O Northcote-Trevelyan Report foi proposto por Stafford Northcote e Charles Trevelyan como uma iniciativa de reforma tendo em vista criar a função pública ao serviço de Sua Majestade do Reino Unido (Her Majesty's Civil Service). Trevelyan trabalhou em diversos relatórios para departamentos ministeriais do governo britânico, tendo chegado à conclusão que se justificaria uma reforma global, aplicada a toda a função pública, baseada nos princípios do mérito e da separação entre tarefas de rotina e tarefas intelectuais. O Northcote-Trevelyan Report reflete estas orientações, propondo nas suas conclusões:

1. Recrutamento para a função pública mediante exames competitivos conduzidos por uma comissão independente;

2. Incentivar o mérito e a iniciativa dos funcionários com base na expectativa de promoção de acordo com o desempenho e recompensa de acordo com os seus méritos em vez de patrocínio, compra ou antiguidade no cargo.

3. Introdução de um sistema de níveis com separação à entrada entre funções de rotina desempenhadas por funcionários administrativos e funções de aconselhamento assumidas por assessores. 
Um ano mais tarde, em 1855, a adoção da Comissão da Função Pública (Civil Service Commission) viria a revelar-se decisiva para o início da implementação destes princípios (O’Toole, 2006). Porém, o seu papel só foi devidamente consolidado em 1870, ano a partir do qual a Comissão fica responsável pelo recrutamento para todos os departamentos da Administração Pública britânica, com a exceção dos Ministérios do Interior (Home Office) e dos Negócios Estrangeiros (Foreign Office) (Pilkington, 1999). Como em muitos outros contextos, Estados Unidos incluídos, a unificação das regras da função pública britânica em termos de salários, condições de trabalho e reputação dos diferentes ministérios demoraria ainda várias décadas, só se considerando alcançada em 1919 (Pilkington, 1999).

\subsection{O Pendleton Civil Service Reform Act (1883)}

\section{e a Adoção do Sistema de Mérito nos Estados Unidos}

Em 1881, o assassinato do presidente James Garfield por Charles Julius Guiteau, um desempregado desiludido com o sistema (disappointed office seeker), concedeu aos defensores da Reforma a oportunidade de culpar o sistema de função pública vigente pelo assassinato do presidente. Este evento trágico, combinado com o mau desempenho dos republicanos nas eleições intercalares de 1882 e o receio da vitória do Partido Democrata nas eleições presidenciais de 1884, que implicaria a substituição nos cargos políticos ocupados por republicanos, criou o ímpeto necessário à aprovação, por parte do Congresso, do Pendleton Civil Service Reform Act, a 16 de janeiro de 1883 (Anagnoson, 2011; Ruhil e Camões, 2003; Theriault, 2003).

O Pendleton Act introduziu nos Estados Unidos da América um sistema de mérito baseado em precedentes britânicos, definindo um sistema de requisitos e organização da função pública baseado nos seguintes princípios (Bilhim, 2017; Anagnoson, 2011; Ruhil e Camões, 2003):

1. Exames competitivos;

2. Relativa segurança de emprego, já que a partir do momento em que os exames passaram a ser usados como critério para nomear os funcionários públicos, estes não podiam ser destituídos de forma arbitrária como sucedia no sistema de despojos;

3. Neutralidade política dos funcionários no exercício das suas funções; 
4. Existência de uma Comissão da Função Pública (Civil Service Commission) incumbida de implementar e monitorizar a aplicação das regras. Esta Comissão permaneceu em exercício até à aprovação do Civil Service Reform Act de 1978;

5. Entradas na função pública efetuadas em qualquer nível da pirâmide, podendo existir entradas laterais. Ao contrário dos sistemas vigentes na Europa Continental, o sistema de mérito americano não adota a ideia de uma burocracia fechada em que os membros ingressam na base na carreira e progridem com o decorrer dos anos.

Tendo o Pendleton Act sido projetado para neutralizar a função pública e remover a influência política das nomeações para os cargos da administração federal, a verdade é que inicialmente esta lei não foi bem-sucedida, pois apenas afetou as funções nos níveis mais baixos da hierarquia. No entanto, a lei concedeu autoridade aos presidentes para expandirem os cargos preenchidos com base no mérito. Nos anos que se seguiram ao Pendleton Act, a função pública tornou-se mais eficiente e menos corrupta, atraindo funcionários mais profissionais que tornaram a burocracia mais eficaz. Ao mesmo tempo, as tarefas diárias do presidente sofreram alterações, com uma diminuição significativa do fardo de preencher centenas de cargos da administração federal (Denhardt, 1995).

As medidas incluídas nesta lei produziram um efeito lento (Anagnoson, 2011). No entanto, tratava-se de uma burocracia modestamente melhor do que a típica da era jacksoniana. O novo sistema permitiu a racionalização da função pública, favorecendo a formação das competências técnicas necessárias para o desenvolvimento de um sistema moderno de administração, autónomo do poder político (Rocha, 2005: 4).

Desde a administração de Andrew Jackson até à de James Garfield, os empregos na função pública eram distribuídos pelos apoiantes partidários. $\mathrm{O}$ Pendleton Act marca a passagem deste sistema de despojos para um sistema de mérito, modelado pelo sistema britânico e pela literatura francesa de Administração Pública, cujo impacto se encontra bem documentado (Martin, 1987). Estas influências foram decisivas para promover a competência neutral dos funcionários públicos assente na dicotomia política-administração proposta por Wilson (1887). Conforme veremos no ponto seguinte, o sistema de 
mérito americano está intimamente ligado a este modelo de Administração Pública, que preconiza a separação entre política e administração.

\section{Influências na Implementação e Consolidação do Sistema de Mérito na Common Law}

No contexto americano, Woodrow Wilson é considerado o pai da Administração Pública enquanto disciplina académica. O seu artigo "The Study of Administration" publicado na revista Political Science Quarterly em 1887 foi o primeiro a abordar de maneira científica e sistemática a questão da administração do governo e do Estado. Para Wilson, a Ciência da Administração tem como objeto de estudo o conhecimento do que o Governo pode executar com sucesso, isto é, de um modo eficaz e eficiente, com o menor dispêndio económico e energético.

A dicotomia entre política e administração é originalmente atribuída a Wilson. Segundo esta interpretação clássica, os políticos decidem sobre políticas públicas através da aprovação de leis, enquanto os administradores aplicam as leis de forma neutra e sem interferência dos políticos. Competiria assim aos políticos a definição das linhas orientadoras das políticas públicas e aos administradores a implementação destas segundo regras de boa gestão e não de acordo com a oportunidade política ou o tempo eleitoral. Daí também que os funcionários deveriam obedecer a regras próprias de atuação, o que na Europa Continental foi denominado de estatuto dos funcionários. Aí se estipula os direitos e deveres, bem como as circunstâncias em que podem ser responsabilizados pelos políticos ou pela hierarquia administrativa. A síntese operada por Wilson reflete bem as ideias que presidiram à criação do sistema de mérito.

Se aquando do nascimento da nação americana se justificava uma orientação política, protagonizada pelos sistemas dos gentlemen e dos despojos, já a sua evolução ditou uma outra orientação a ser adotada. É com o crescendo em complexidade e em número de funções do governo que a questão do mérito se torna relevante e a Ciência da Administração se vai consolidar como caminho para a gestão da organização pública, de forma a satisfazer aqueles que dela necessitam.

Nos Estados Unidos da América, as regras de funcionamento da burocracia receberam a influência da Administração Científica do Trabalho, que, entretanto, se desenvolvia no domínio empresarial por iniciativa de Frederick Taylor (Horton, 2011). A preocupação original de Taylor era acabar com o 
desperdício e perdas sofridas pelas empresas e elevar os níveis de produtividade por meio da aplicação de métodos e técnicas de engenharia industrial. Tal como este engenheiro de profissão procurou aplicar o método científico à gestão na procura da eficiência industrial, também Wilson advogou a administração pública como ciência. Wilson acreditava que os estudiosos da política tinham uma preocupação excessiva com as questões constitucionais e ignoravam as operações ativas e práticas de como gerir agências governamentais. Com o crescimento do governo, estas operações tornaram-se cada vez mais relevantes e daí a afirmação de que «é mais difícil administrar uma constituição do que elaborar uma»(Wilson, 1887: p. 200). Estas reformas, conjuntamente com a tradição burocrática do continente europeu, criaram o ambiente propício ao aparecimento do sistema de mérito.

Embora influenciado pelo Pendleton Civil Service Reform Act no que se referia à gestão de pessoal, Wilson pretendia também estudar a organização e os métodos de governo, sofrendo assim influência da tradição administrativa europeia e do pensamento de Max Weber em particular. O modelo organizacional (teórico) proposto por Weber influenciou o pensamento e a prática desejada por Wilson, nomeadamente o mérito como critério preponderante, a profissionalização dos agentes, a definição de normas e procedimentos para a ação e a competência técnica como crucial para a tomada de decisão, entre outros aspetos (Barberis, 2011).

Na tradição de Weber, Wilson sugeriu igualmente que para gerir eficientemente um governo é necessário optar pela racionalização do trabalho. Esta posição surge num contexto de expansão dos métodos de gestão privada e do intensificar da corrente da administração científica do trabalho. Estes aspetos foram rapidamente importados pelas organizações do setor público. Em comum a ambas, a divisão do trabalho e a especialização, a análise e o desenho de funções, a formalização da comunicação entre os trabalhadores e a substituição da improvisação pela ciência, através do planeamento dos métodos de trabalho.

As proposições que integram o paradigma wilsoniano para a gestão de pessoal são, assim, parcialmente influenciadas e congruentes com a Administração Pública francesa, a Teoria da Burocracia de Max Weber e com os princípios da administração científica do trabalho desenvolvidos por Frederick Taylor. Esta confluência de fatores permitiu o surgimento do movimento da reforma progressista (Progressive Reform) do final do século xIx e início do 
século $\mathrm{xx}$, que procurou institucionalizar a separação política-administração e consolidar o sistema de mérito. Resumindo, a Progressive Reform procurou:

1. A prossecução de uma burocracia representativa capaz de gerar justiça social e equidade e que conduziu à adoção do sistema de mérito no âmbito do Pendleton Act de 1883;

2. Uma identidade e legitimação para a administração pública enquanto disciplina científica, com regras generalizáveis e princípios válidos para todas as posições e estruturas organizacionais. Verificou-se uma tentativa evidente de criar uma organização governamental essencialmente técnica e não política de forma a legitimar o campo científico. Esta iniciativa abriu caminho para a investigação e descoberta de princípios científicos universais semelhantes às leis da física (Knott e Miller, 1987);

3. Ultrapassar a elevada rotação de pessoal e assegurar a longevidade da profissão, o que é consistente com o objectivo dos partidários da Progressive Reform de combater a corrupção do sistema de despojos e das máquinas políticas. A introdução do sistema de despojos teve como principal finalidade permitir a influência das massas sobre a política, mas produziu o efeito indesejado da substituição de funcionários sempre que uma nova administração era eleita. Os reformadores acreditavam que o isolamento da Administração Pública em relação à política asseguraria a continuidade dessa mesma Administração e produziria ganhos significativos em economia e eficácia;

4. A profissionalização dos agentes da Administração era algo desejado e só possível com a definição de um elevado número de competências exclusivas.

5. Por último, a dicotomia política-administração foi alimentada pelo trabalho filantrópico desenvolvido pela Fundação Rockefeller, que promoveu uma agenda de apoio à investigação que perpetuou a dicotomia. Alasdair Roberts (1994) sugere que a dicotomia foi usada como estratégia retórica que permitiu o desenvolvimento da disciplina nos seus primeiros anos. Os assuntos políticos foram negligenciados com o argumento de que não eram científicos e, como tal, não deveriam 
ser apoiados. Por isso, a demonstração de neutralidade por parte da Administração Pública institucionalizou-se também devido a preocupações pragmáticas com o financiamento.

As pressões para a institucionalização da dicotomia ajudaram ao desenvolvimento da formação em Administração Pública baseada na gestão e à consolidação do sistema de mérito. $\mathrm{O}$ modelo gestionário proposto no primeiro livro de texto nos Estados Unidos - Introduction to the Study of Public Administration (1926) de Leonard White - é igualmente consistente com um sistema administrativo menos elitista e hierárquico do que sucedia na Europa Continental (Stillman, 1997).

White interessou-se pela história institucional do governo federal norte-americano - ramo que até então não havia sido considerado. Este movimento intelectual foi reforçado pela Grande Depressão (1929-1932), que veio dar outra importância ao estudo da Administração Pública federal devido ao acréscimo da procura dos serviços básicos e bens essenciais para a sobrevivência da população. Tal incremento da procura teve como consequência o impulso da disciplina na sua orientação gestionária, através da consideração da redução da despesa pública, de um maior desempenho das organizações públicas através da consideração do seu desenho organizacional e da dotação da função pública de pessoal qualificado capaz de fazer uma melhor utilização dos recursos escassos.

\section{Do Pendleton Act (1883) ao Civil Service Reform Act (1978)}

Desde a aprovação do Pendleton Act em 1883 até à administração do presidente Franklin Roosevelt (1933-1945), o sistema de mérito desenvolveu-se de forma lenta (Tsao e Worthley, 2009). A eficácia e a eficiência tornaram-se valores fundamentais na administração federal e o mérito intrínseco dos candidatos tornou-se o critério dominante no recrutamento e seleção dos funcionários. Exames abertos e competitivos, ênfase na neutralidade política, seleção a partir dos três primeiros classificados do processo de recrutamento e introdução de um sistema de remuneração para toda a administração federal foram as principais medidas operacionais para a implementação do sistema de mérito (Woodard, 2005).

Em 1931, a Comissão da Função Pública acumulava responsabilidade pela classificação de funções, notações de eficiência e administração das pensões dos funcionários. A centralização crescente de funções tornou a gestão de 
pessoal na administração federal ineficaz, mais focada em regras restritivas e regulamentos (Rosenbloom, 1989).

Roosevelt, um forte defensor da função pública e do sistema de mérito, deu um novo impulso à Comissão da Função Pública (Anagnoson, 2011; Kutler, 2003). Era consensual a crença de que funcionários públicos competentes e comprometidos eram essenciais para uma conduta profissional do governo (Tsao e Worthley, 2009). Deste modo, Roosevelt insistiu na importância do mérito nas nomeações, reforçou a Comissão da Função Pública, impulsionou a atividade sindical dos funcionários públicos e reorganizou os departamentos executivos de modo a melhorar a eficiência. Ao mesmo tempo, porém, o Hatch Act de 1939 proibiu a atividade político-partidária dos funcionários da administração federal, numa tentativa de combater a diminuição da neutralidade política sentida ao longo da década de 1930 (Tsao and Worthley, 2009). Com a administração Roosevelt iniciou-se um longo processo de descentralização da gestão de pessoal para os departamentos e agências federais que, mais tarde, a partir da administração Truman (1945-1953), assumiram a análise de categorias funcionais, a avaliação de desempenho e a gestão das promoções, entre muitas outras tarefas. Neste contexto, Roosevelt foi apelidado de «pai» da «moderna função pública baseada no mérito» (Anagnoson, 2011: p. 128).

Após a II Guerra Mundial, o número de nomeações com base nos princípios do clientelismo diminuiu substancialmente, em parte devido à iniciativa da administração Roosevelt em estender o sistema de mérito «para cima, para baixo e para os lados», cobrindo todos os cargos não relacionados com a definição de políticas públicas (Stillman, 1999: p. 123). Assim, na reta final da administração Truman, 95 por cento das nomeações eram já feitas com base no sistema de mérito (Anagnoson, 2011).

No entanto, a partir da década de 1950, algumas exceções à admissão por mérito começaram a ser admitidas, nomeadamente as relacionadas com a valorização de grupos fragilizados, como sejam veteranos de guerra, estudantes e pessoas portadoras de deficiência. Nas administrações seguintes acentuou-se a preocupação com os direitos civis das mulheres e das minorias, transformando a justiça e a equidade em valores fundamentais da gestão dos recursos humanos no setor público. A reação surgiu por parte daqueles que achavam que o tratamento justo e equitativo não se deveria sobrepor ao mérito intrínseco dos candidatos aos lugares da função pública. Mais tarde, a partir da 
década de 1990, os programas de affirmative action procuraram combinar critérios de equidade e justiça social com o critério do mérito (Woodard, 2005).

Ao longo dos anos, o desenvolvimento da punção pública americana resumiu-se a uma incessante procura pelo equilíbrio entre a necessidade de experiência administrativa por parte dos governos e a responsabilização da administração perante o regime político (Tsao e Worthley, 2009). Em relação às administrações anteriores, a administração Nixon acentuou esta segunda vertente, acompanhada da tradicional desconfiança e relutância das administrações do Partido Republicano em valorizar a função pública, favorecendo a redução do número de funcionários públicos e a transferência de cargos executivos e de nomeados políticos. Além disso, e contrariamente às administrações do Partido Democrata, restringiu-se o desenvolvimento da atividade sindical dos funcionários como, por exemplo, a proibição de participação em greves (Anagnoson, 2011). Em virtude destas orientações contraditórias, em 1973 ainda se mantinha uma visão tradicional da Administração Pública, com os nomeados políticos envolvidos na elaboração de políticas públicas, a função pública envolvida na Administração e nenhum destes grupos envolvidos na política partidária (Anagnoson, 2011; McGrath, 2013).

Somente com a administração de Jimmy Carter (1977-1981) a função pública americana foi alvo de uma profunda e verdadeira reforma, resultando na revogação de uma peça de legislação - o Pendleton Act - que persistiu ao longo de quase cem anos. E se, em 1883, o Pendleton Act consagrou a noção de mérito na administração governamental através de práticas que permitiam reduzir a influência da política na seleção de funcionários públicos para cargos de carreira, a Lei de Reforma da Função Pública (Civil Service Reform Act), aprovada em 1978, foi projetada para consagrar, de igual modo, a capacidade de resposta burocrática ao regime político, protegendo os funcionários públicos contra a interferência política (Woodard, 2005; Tsao e Worthley, 2009).

Para contrariar a instabilidade e o mal-estar público resultante de uma crescente desconfiança no governo associada à perceção de mau desempenho, esta nova Lei procurou manter o princípio do mérito, mas a gestão de recursos humanos na administração federal foi ainda mais descentralizada e delegada nos departamentos e agências federais, de modo a flexibilizar a gestão de pessoal. Como resultado deste movimento, as práticas do sistema de mérito passaram a variar em função da negociação coletiva ocorrida no seio de cada uma destas unidades. No mesmo sentido, o anterior sistema de compensação estabelecido para toda a administração federal começou a desagregar-se, com 
a adoção de sistemas locais de compensação, sistemas especiais para lugares de difícil preenchimento e bandas experimentais de pagamento (Woodward, 2005). O conteúdo desta nova lei foi indubitavelmente influenciado pelos desenvolvimentos na teoria e na prática da gestão pública, procurando dar uma resposta às exigências do público por um governo mais eficiente e responsável (McGrath, 2013).

Contudo, estudos empíricos da década de 1980 confirmam a ideia de que as regras rígidas de gestão de pessoal no setor público se mantinham, afetando negativamente a relação entre desempenho e recompensas extrínsecas e a capacidade dos gestores públicos para aplicarem essas recompensas (Rainey, 1983). Paradoxalmente, regras, regulamentos e práticas inflexíveis destinadas a proteger os funcionários públicos da intromissão arbitrária dos políticos criaram um contexto em que não só o mérito não era reconhecido, como não conseguiam assegurar o controlo e a prestação de contas perante os eleitos e seus nomeados (accountability) (Woodard, 2005).

A lei aboliu a Civil Service Commission, criando em seu lugar dois novos organismos. O primeiro, designado Office of Personnel Management (OPM) era liderado por um diretor nomeado pelo presidente e tinha como objetivo principal gerir os recursos humanos da administração federal. O segundo, o Merit Systems Protection Board, mantinha a natureza independente da Civil Service Commission, mas agora com poderes mais limitados e focados na audição de atividades contra o sistema de mérito, na revisão de regras emanadas do OPM capazes de colocar em risco o sistema de mérito e na investigação de queixas por práticas de gestão de pessoal inadequadas (Schuman e Olufs III, 1988).

A administração Carter criou ainda um Senior Executive Service, composto por altos cargos administrativos, para alcançar um maior equilíbrio entre a neutralidade política e a eficácia organizacional, permitindo aos políticos nomeados um maior controlo sobre a função pública federal (Anagnoson, 2011; Tsao e Worthley, 2009). O objetivo era criar um quadro de funcionários altamente qualificados caracterizado por maior prestígio, maior profissionalismo e maior competência. Ao contrário do que sucedia em níveis hierarquicamente inferiores da Administração, estes quadros de topo poderiam mover-se entre agências federais, levando consigo o prestígio mais associado à pessoa do que à posição (Schuman e Olufs III, 1988).

Esta nova Lei de Reforma da Função Pública procurou ainda colmatar algumas das críticas de que o sistema de mérito foi alvo ao longo dos anos. 
Essencialmente, os críticos sustentavam que a obrigatoriedade do sistema de mérito restringia a atuação dos gestores de recursos humanos, contribuindo para a existência de desperdícios e atrasos processuais (McGrath, 2013). Assim, os princípios do sistema de mérito foram codificados para orientar as políticas e práticas da gestão de recursos humanos, tornando as entidades responsáveis pela gestão de recursos humanos mais descentralizadas e promovendo uma maior discricionariedade na tomada de decisões por parte dos gestores (Woodard, 2005).

\section{Da National Performance Review (1993) à Atualidade}

Ao longo da década de 1980 e início da década de 1990, os desenvolvimentos da gestão pública deram origem ao que hoje denominamos como Nova Gestão Pública, iniciada nos países da common law, e, no caso dos Estados Unidos da América, ao movimento de Reinvenção do Governo (Gore, 1996; McGrath, 2013; Bilhim, 2017). Neste contexto, e contrariamente a outras administrações, sobretudo republicanas, a administração do presidente Bill Clinton (1993-2001) demonstrou um grande interesse em melhorar a Administração Pública federal, pelo que o vice-presidente Al Gore liderou a elaboração de um relatório sobre o estado da Administração Pública americana, defendendo a necessidade de reinvenção da mesma, num processo que ficou conhecido como National Performance Review (Gore, 1996; Kettl, 2000; Thompson, 2000). A principal perspetiva deste programa mantinha o nexo de causalidade entre a teoria e a prática para resolver os problemas governamentais, mas reformou de forma efetiva o sistema de mérito na função pública, indo muito mais além do que qualquer outra reforma anterior (McGrath, 2013).

O fator distintivo do Relatório Gore é a defesa da rutura com o paradigma burocrático de origem weberiana, wilsoniana e taylorística, vigente ao longo dos últimos duzentos anos, dando lugar a uma administração empresarial com a missão de funcionar melhor e gastar menos (Gore, 1996). Os defensores desta nova perspetiva advogavam que: «i) a gestão na Administração Pública e no setor privado, embora de natureza distinta, têm aspetos comuns, devendo promover a satisfação do utente (encarado como cliente), dar poder de decisão aos trabalhadores diretamente intervenientes e estimular a excelência e a qualidade; ii) a gestão dos serviços públicos tem que possuir uma clara perceção da missão a cumprir, recorrer mais a incentivos e menos à imposição de regulamentos, adotar a ideia de que trabalha bem quem consegue obter bons resultados (e não quem se limita a dar estrito cumprimento a regras e procedi- 
mentos), medir os resultados em função do grau de satisfação do cliente e refletir devidamente as prioridades orçamentais; iii) os serviços públicos devem funcionar o mais possível em situação de concorrência, interna e externa; e iv) o número de funcionários públicos federais pode e deve ser reduzido, sem que diminua, antes devendo aumentar, a eficácia e a produtividade» (Gore, 1996: p. 17).

Após a avaliação do estado da Administração Pública americana, o Relatório Gore propôs «caminhos de mudança, a partir de uma nova filosofia de gestão, na qual se inspiram as cerca de 384 recomendações apresentadas, implicando a adoção de cerca de 1200 medidas concretas» (Gore, 1996: p. 9). O conjunto de ideias presentes neste relatório podem ser sintetizadas em quatro princípios-base: i) eliminar a burocracia; ii) colocar os clientes em primeiro lugar; iii) dar competências aos funcionários para obter resultados; e iv) regressar ao fundamental: melhor Administração, por menos dinheiro.

Naturalmente, e mediante as críticas preconizadas pela National Performance Review quanto ao facto de os sistemas modernos de gestão de recursos humanos impedirem os gestores públicos de se focarem num desempenho mais eficiente, em matéria de gestão de recursos humanos as recomendações do relatório Gore incluíam a desregulação, a descentralização e a simplificação dos sistemas, visando igualmente a necessidade de recompensar os funcionários públicos produtivos e disciplinar os funcionários com um desempenho mais baixo (French e Goodman, 2012; McGrath, 2013). Em concreto, o Relatório Gore apresenta 14 recomendações para reinventar a Administração Pública americana. De entre estas, destacam-se algumas com implicações diretas para o reconhecimento do mérito, como sejam a flexibilização do recrutamento tendo em vista a promoção da sua eficácia, as alterações aos sistemas de classificação e de cálculo das remunerações, a criação de sistemas de prémios e bónus para melhorar o desempenho individual e a capacitação do Senior Executive Service para estimular a mudança cultural em toda a Administração Pública (Gore, 1996: pp. 367-369). Em síntese, muitas das ideias da reinvenção da governação em matéria de gestão de recursos humanos concentraram-se nas regras e procedimentos burocráticos, na cooperação entre gestores e funcionários, na assistência e na formação dos funcionários públicos e no desenho e estrutura das organizações hierárquicas (French e Goodman, 2012).

A administração de George W. Bush enfatizou os valores políticos e a responsabilização perante o regime, demonstrando, uma vez mais, um ajustamento cíclico do equilíbrio entre a ênfase na competência técnica e neutra- 
lidade política da administração e o realçar de um modelo mais político de administração enfatizando a lealdade perante o chefe do executivo e os seus nomeados (Riccucci e Thompson, 2008; Tsao e Worthley, 2009).

É bom notar que o sistema de mérito no contexto da burocracia federal americana tem os seus críticos e o movimento recente de flexibilização do emprego (at-will employment) pretende acabar com o regime de permanência (tenure) na Administração Pública americana para aumentar a sua eficiência. Num conjunto de artigos altamente controversos, Maranto (1998; 2001; 2002) propôs a abolição do regime de permanência na função pública americana e a sua substituição por um regime exclusivo de nomeação política assente na responsabilização. Para Maranto, a administração federal caracteriza-se por um conjunto alargado de funcionários cujo contributo é diminuto e que não podem ser afastados devido às regras rígidas contra os despedimentos contidas no regime de permanência. Assim, o sistema de mérito, que foi introduzido com o objetivo de garantir que apenas os melhores assumiriam cargos na administração federal, apresenta-se hoje distorcido e a precisar de reforma. $\mathrm{O}$ autor argumenta ainda que esta reforma poderia potencialmente ser aplicada também aos estados americanos, embora o seu sucesso ao nível estadual esteja condicionado, em alguns estados, pelo escrutínio limitado por parte dos media, pela competição política reduzida, pela fraqueza das burocracias existentes e pela tolerância relativamente elevada para políticas de despojos (Maranto e Johnson, 2008).

No entanto, a tendência para a adoção de sistemas mais flexíveis a todos os níveis da Administração americana parece ser já incontornável. Nigro e Kellough (2008) refletem sobre as reformas da função pública ao nível dos estados e constatam que as tendências dominantes incluem a descentralização, a desregulação e a redução da proteção de emprego aos funcionários públicos, com alguns estados (como a Florida e a Geórgia) a optarem pela substituição do sistema de mérito por um sistema de flexibilidade de emprego (at-will system), com efeitos exatos ainda por determinar ao nível dos direitos dos funcionários públicos, da duração dos processos de recrutamento e seleção, do tratamento equitativo dos funcionários e do efeito na produtividade do pagamento com base no desempenho. Os escassos estudos existentes sobre o impacto do sistema at-will sugerem que este tem um efeito negativo na motivação e nas iniciativas de inovação propostas pelos funcionários públicos, sobretudo minorias, com consequências igualmente nefastas para a produtividade (Battaglio, Jr., 2010). 


\section{Conclusões}

Atualmente, a seleção de funcionários para a Administração Pública tende a privilegiar uma combinação entre seleção baseada no mérito e escolhas políticas, de modo a assegurar a continuidade da expertise e a capacidade de resposta às solicitações dos políticos eleitos. A profissionalização dos quadros da Administração já não é puramente técnica, baseando-se antes no pressuposto de que o novo modelo de governação é inerentemente político e requer uma competência normativa, constitucional e retórica (Green et al., 1993).

A razão para esta combinação prende-se com a necessidade de assegurar, simultaneamente, a competência técnica indispensável à prossecução de tarefas complexas e o controlo político da burocracia, tão necessário ao cumprimento das orientações da Presidência. De facto, uma análise do equilíbrio entre funcionários de carreira selecionados com base no mérito e assessores politicamente nomeados nos 50 estados norte-americanos entre 1987 e 2002 indica que, nos estados nos quais este equilíbrio é maior, a burocracia apresenta níveis mais elevados de competência e desempenho (Krause et al., 2006). Este equilíbrio deve ainda assegurar a continuidade de funcionários com elevada experiência acumulada. A sua saída em massa por desacordo com os nomeados políticos pode resultar em consequências desastrosas para uma agência governamental que perca grande parte dessa expertise (Bertelli e Lewis, 2013).

A principal conclusão que se pode retirar de uma análise do sistema de mérito no âmbito da administração federal americana é que o conceito de mérito evoluiu, em virtude da crescente descentralização e desregulação da função pública e da ausência de uma definição política e legal universal de mérito. A tendência atual aponta para «um reforço dos valores de justiça social e equidade no contexto das políticas públicas e da lei, com a gestão de pessoas a ser cada vez mais definida localmente por dirigentes, trabalhadores, sindicatos, cidadãos e solicitações da política e da sociedade, o que conduz a organizações com flexibilidade para desenvolver os seus próprios sistemas de capital humano.» (Woodard, 2005: p. 115). A consequência mais evidente desta descentralização e desregulação da função pública no contexto americano é uma maior necessidade de prestação de contas e supervisão, de modo a continuar a assegurar elevados padrões de desempenho que garantam a eficácia e eficiência na administração pública e, simultaneamente, evitem a influência indevida, o favoritismo e a discriminação (Romzek, 1997; Woodard, 2005). A noção de mérito é hoje, por isso mesmo, muito menos monolítica do 
que no passado, prevendo-se que continue a evoluir no sentido de constante adaptação a ambientes cada vez mais complexos e dinâmicos.

\section{Referências}

Anagnoson, J. T. (2011). The United States civil service. In A. Massey (Eds.). International handbook on civil service systems (pp. 125-151). Cheltenham: Edward Elgar.

Barberis, P. (2011). The Weberian legacy. In A. Massey (Eds.). International handbook on civil service systems (pp. 13-30). Cheltenham: Edward Elgar.

Battaglio, Jr., R. P. (2010). Public service reform and motivation: evidence from an employment at-will environment. Review of Public Personnel Administration, 30(3), 341-363. DoI: <10.1177/0734371X10368224>.

Bertelli, A., \& Lewis, D. (2012). Policy influence, agency-specific expertise, and exit in the federal service. Journal of Public Administration Research and Theory, 23, 223-245. <DoI:10.1093/jopart/mus044>.

Bilhim, J. A. (2017). Nova governação pública e meritocracia. Sociologia, Problemas e Práticas, 84, 9-25. DoI: <10.7458/SPP2017849462>.

Bowman,J.(1999).Performanceappraisal:verisimilitudetrumpsveracity.PublicPersonnel Management, 28(4), 557-576. DOI: <10.1177/009102609902800406>.

Denhardt, R.B. (1995). Public Administration: An Action Orientation. 2. ${ }^{\text {a }}$ Ed. Orlando, FL: Harcourt Brace \& Co.

French, P. E., \& Goodman, D. (2012). An assessment of the current and future state of human resource management at the local government level. Review of Public Personnel Administration, 32(1), 62-74. DoI: <10.1177/0734371X11421499>.

Gailmard, S., \& Patty, J. (2007). Slackers and zealots: civil service, policy discretion, and bureaucratic expertise. American Journal of Political Science, 51(4), 873-889. DOI: <10.1111/j.1540-5907.2007.00286.x >.

Gore, A. (1996). Reinventar a Administração Pública: Da burocracia à eficácia: Para governar melhor e poupar milhões. Lisboa: Quetzal Editores.

Green, M. (2000). Beware and prepare: The government workforce of the future. Public Personnel Management, 29(4), 435-443. DoI: <10.1787/19934351>.

Green, R., Wamsley, G., \& Keller, L. (1993). Reconstituting a profession for American public administration. Public Administration Review, 53(6), 516-524. DOI: $<10.2307 / 977361>$.

Horton, S. (2011). Contrasting Anglo-American and Continental European civil service systems. In A. Massey (Eds.). International handbook on civil service systems (pp. 31-53). Cheltenham: Edward Elgar. 
Kaufman, H. (1956). Emerging conflicts in the doctrines of Public Administration. American Political Science Review, 50(4), 1057-1073.

Kettl, D. F. (2000). Public Administration at the Millennium: The State of the Field. Journal of Public Administration Research and Theory, 10(1): 7-34.

Klingner, D., \& Lynn, D. (1997). Beyond civil service: The changing face of public personnel management. Public Personnel Management, 26(2), 157-174. DOI: $<10.1177 / 009102609702600201>$.

Knott, J. H. \& G. J. Miller. (1987). Reforming bureaucracy: The politics of institutional choice. Englewood Cliffs, NJ: Prentice-Hall.

Krause, G., Lewis, D., \& Douglas, J. (2006). Political appointments, civil service systems, and bureaucratic competence: Organizational balancing and executive branch revenue forecasts in the American states. American Journal of Political Science, 50(3), 770-787. DoI: <10.1111/j.1540-5907.2006.00215.x>.

Kutler, S. I. (2003). Dictionary of American history: Vol.2. (3th ed). New York: Thomson Learning.

Maranto, R., \& Johnson, J. (2008). Bringing back boss tweed? Could at-will employment work in state government and, if so, where?. International Journal of Public Administration, 31(5), 468-488. DoI: <10.1080/01900690701624097>.

Martin, D. (1987). Déjà vu: French antecedents of American public administration. Public Administration Review, 47(4), 297-303. DoI: <10.2307/975309>.

McGrath, R. J. (2013). The rise and fall of radical service reform in the U.S. States. Public Administration Review, 73(4), 638-649. DoI: <http://dx.doi. org/10.1111/puar.12075>.

Nigro, L., \& Kellough, J. (2008). Personnel reform in the states: a look at progress fifteen years after the winter commission. Public Administration Review, 68, S50-S57. DoI: $<10.1111 / \mathrm{j} .1540-6210.2008 .00978 . \mathrm{x}>$.

O'Toole, B. J. (2006). The ideal of public service: Reflections on the higher civil service in Britain. London: Routledge.

Parry, R. (2011). The United Kingdom civil service: A devolving system. In A. Massey (Eds.). International handbook on civil service systems (pp. 347367). Cheltenham: Edward Elgar.

Pilkington, C. (1999). The civil service in Britain today. Manchester: Manchester University Press.

Rainey, H. (1983). Public agencies and private firms - Incentive structures, goals and individual roles. Administration \& Society, 15(2), 207-242. DOI: $<10.1177 / 009539978301500203>$. 
Riccucci, N. M. \& F. J. Thompson. (2008). New Public Management, Homeland Security, and the Politics of Civil Service Reform. Public Administration Review, 68(5): 877-90.

Roberts, A. (1994). Demonstrating neutrality: The Rockfeller philantropies and the evolution of Public Administration, 1927-1936. Public Administration Review, 54(3): 221-227.

Rocha, J.A. (2005). Quadro geral da evolução da gestão de recursos humanos na administração pública. Artigo apresentado na Conferência no Instituto Superior de Contabilidade e Administração de Lisboa (ISCAL). Lisboa.

Rosenbloom, D. H. (1989). Public administration: Understanding management, politics, and law in the public sector. New York: McGraw-Hill.

Ruhil, A. V. S., \& Camões. P. J. (2003). What lies beneath: The political roots of state merit systems. Journal of Public Administration Research and Theory, 13(1), 27-42. DoI: <https://doi.org/10.1093/jpart/mug006>.

Schuman, D. \& Oluffs, D.W. (1998). Public Administration in the United States. Lexington, MA: D.C. Heath and Company.

Stillman, R. (1997). American vs. European public administration: Does public administration make the modern state, or does the state make public administration?. Public Administration Review, 57(4), 332-338. DOI: $<10.2307 / 977316>$.

Theriault, S. M. (2003). Patronage, the Pendleton Act, and the power of the people. Journal of Politics 65(1), 50-68. DoI: <10.1111/1468-2508.t01-1-00003>.

Thompson, J. R. (2000). Reinvention as a Reform: Assessing the National Performance Review. Public Administration Review, 60(6), 508-521.

Ting, M. M., Snyder, J. M., Hirano, S., \& Folke, O. (2012). Elections and reform: The adoption of civil service systems in the U.S. states. Journal of Theoretical Politics, 25(3), 363-387. DOI: <10.1177/0951629812453217>.

Tsao, K. K., \& Worthley, J. A. (2009). Civil service development in China and America: A comparative perspective. Public Administration Review, 69, S88-S94. DOI: $<10.1111 /$ j.1540-6210.2009.02094.x>.

Waxin, M., \& Bateman, R. (2009). Public sector human resource management reform across countries: from performance appraisal to performance steering? European Journal of International Management, 3(4), 495-511. DOI: $<$ http://dx.doi.org/10.1504/EJIM.2009.028852>.

Weber, M. (1947). The theory of social and economic organizations. New York: Oxford University Press. 
White, L. (1926) Introduction to the Study of Public Administration. New York: Macmillan Co.

Wilson, W. (1887). The Study of Public Administration. Political Science Quarterly, 2(2), 197-222. DoI: <10.2307/2139277>.

Woodard, C. A. (2005). Merit by any other name - Refraining the civil service first principle. Public Administration Review, 65, 109-116. DoI: <10.1111/ j.1540-6210.2005.00435.x>. 